\title{
Evaluation of healthy lifestyle behaviors and affecting factors of hemodialysis patients
}

\author{
Ayşenur Sarıaslan' $^{(\mathbb{D}}$, Mehtap Kavurmacı $^{2^{*}}$ \\ ${ }^{1}$ Department of Internal Medicine Nursing, Nursing Faculty, Kafkas University, Kars, Turkey \\ ${ }^{2}$ Department of Internal Medicine Nursing, Nursing Faculty, Atatürk University, Erzurum, Turkey
}

Correspondence to:

Mehtap Kavurmacı, E-mail:

m.curcani@hotmail.com

Received: 22 Oct. 2020 Accepted: 20 Nov 2020 ePublished: 4 Dec. 2020

Keywords: Hemodialysis, Healthy lifestyle behaviors, Nursing

\begin{abstract}
Introduction: Nurses should carry out the necessary research, training and counseling services to guide hemodialysis (HD) patients in acquiring healthy lifestyle behaviors.

Objectives: This study was conducted to determine the healthy lifestyle behaviors in HD patients and affecting factors.

Patients and Methods: This descriptive study was conducted at a university hospital in Eastern Turkey between November 13, 2017 and November 16, 2018. The study was carried out with 140 patients who were registered in the HD units of the relevant hospitals and met the sampling criteria. The study data were collected using the patient introduction form and the Health-Promoting Lifestyle Profile II (HPLP II). Results: Patients' mean total score in the HPLP II was found to be $117.80 \pm 37.07$. When we look at the mean scores of the patients in the sub-scales, it was found that the highest mean score was $22.44 \pm 7.01$ points in the health responsibility sub-scale and the lowest mean score was $14.38 \pm 6.70$ points in the physical activity sub-scale.

Conclusion: As a result of the study, patients were found to have moderate healthy lifestyle behaviors and very low physical activity scores. Based on these results, it is recommended to organize special exercise programs in order to increase the physical activity levels of HD patients with low levels of activity.
\end{abstract}

Citation: Sarıaslan A, Kavurmacı M. Evaluation of healthy lifestyle behaviors and affecting factors of hemodialysis patients. J Prev Epidemiol. 2020;5(2):e19. doi: 10.34172/jpe.2020.19.

\section{Introduction}

As a common health problem in the world chronic renal failure (CRF) is characterized by chronic, inflammatory and degenerative changes in renal parenchyma due to various etiology, and decreased glomerular filtration rate (GFR) due to progressive deterioration in renal function $(1,2)$. which leads to endstage renal disease (ESRD) when GFR decreases to $5-10 \mathrm{~mL} / \mathrm{min}(3)$.

Around 1000 people per million population in the world develop ESRD and it is estimated that this ratio will increase more than twice in the next decade (4). In the United States, about 100 people per million population develop CRF each year. When the number of patients with CRF per million population (pmp) was examined in some countries around the world, it was 527 pmp in Taiwan, 362 pmp in JaliscoMexico, 2309 pmp in Japan, $1924 \mathrm{pmp}$ in the USA, 1662 pmp in Portugal and $1661 \mathrm{pmp}$ in Singapore. The ESRD point prevalence, requiring renal replacement therapy (RRT) in Turkey has been found to increase 933 per million population in 2016 from 578 per million population in 2006 (5).

\begin{abstract}
Key point
Nurses should carry out the necessary research, training and counseling services to guide hemodialysis patients in acquiring healthy lifestyle behaviors. This study was conducted for evaluation of healthy lifestyle behaviors and affecting factors of hemodialysis patients. As a result of the study, patients were found to have moderate healthy lifestyle behaviors scores and very low physical activity scores. Based on these results, it is recommended to organize special exercise programs in order to increase the physical activity levels of hemodialysis patients.
\end{abstract}

A variety of life-saving RRTs are applied to patients diagnosed with CRF. Hemodialysis (HD) is the most common RRT method. A successful HD is closely related to drug treatment, regular dialysis, fluid restriction, and adherence to appropriate nutrition programs as a way of life (6). While these behaviors become a lifestyle, they restrict physical, emotional and social functions, and the individuals become unsatisfied with their life and their quality of life decreases (7). In order to improve the quality of life of HD patients, it is quite important to ensure their adherence to treatment and guide them to acquire healthy lifestyle behaviors (8). 
For individuals to acquire a positive health behavior, it is necessary to determine whether the individual is conducting a specific behavior and the factors affecting this behavior. Therefore, many models have been developed to evaluate the behavior process. One of these models is the Health Promotion Model. The model, developed by Pender in 1982-1984, on the basis of the social learning theory, is intended to explain health-promoting behaviors (9).

Nurses have important roles in guiding HD patients to have a healthy lifestyle. Nurses should evaluate their healthy lifestyle behaviors as well as the factors affecting these behaviors, and should conduct the necessary research, training and consultancy services in order to guide $\mathrm{HD}$ patients to acquire healthy lifestyle behaviors $(9,10)$.

\section{Objectives}

This study was conducted to determine the healthy lifestyle behaviors in HD patients and affecting factors.

\section{Patients and Methods}

\section{Study design}

This descriptive study was conducted at a university hospital in Eastern Turkey between November 13, 2017 and November 16, 2018. The study population consisted of 151 patients registered in the HD center of the related hospital.

Before the collection of study data, the approval of ethics committee was obtained from the Ethics Committee of University, Faculty of Health Sciences. After obtaining the approval of the ethics committee for the study, the necessary institution permissions were obtained from the studied hospitals. It was explained to CRF patients that they are free in their decision to participate in the research in accordance with the principle of "Respect for Autonomy", the "Confidentiality and Protection of Privacy" principle was met by stating that the information obtained will be kept confidential, and it was stated that identity of respondents will be secure in accordance with the principle of "Anonymity and Secrecy", and "Beneficence and Non-Maleficence" ethical principle was fulfilled in general.

Patients who were 18 years of age and over, had no psychiatric disorder and had no communication barrier, and who received HD treatment for at least 6 months and who agreed to participate in the research were included in the study. Without any sample selection, it was aimed to reach all the study population, but 11 patients were excluded from the study since four of the patients refused to participate in the research, five were receiving HD treatment for less than six months, one patient had speech impairment and one patient had hearing impairment.

Of the study population, $92.7 \%$ was reached and 140 patients were included in the study sample. The research data were collected by the researcher in the HD units of the relevant hospitals. The data were collected by one-toone interview method in a suitable room in the HD unit after explaining the purpose of the research to the patients and obtaining their verbal consent. Each interview lasted approximately 7-10 minutes.

Research findings were limited to patients with CRF treated in HD units of the related hospitals.

\section{Instruments}

The Patient Information Form and Health-Promoting Lifestyle Profile II (HPLP II) scale were used for the collection of the research data.

\section{Patient information form}

Patient Information Form, which was used for the collection of research data, was developed by the researchers in line with the literature (11-14). The patient information form includes items to determine the socio-demographic and disease-specific characteristics of the patients.

\section{Health-Promoting Lifestyle Profile II}

Turkish validity and reliability study of the scale, which has been developed in 1987 by Walker, Sechrist and Pender originally, has been conducted by Bahar et al in 2008 $(13,15)$. The scale measures health-promoting behaviors of individuals in relation to a healthy lifestyle (16). The original scale's sub-scales were revised to obtain higher alpha levels $(13,17)$. Turkish validity and reliability study of the renewed HPLP II scale was carried out by Bahar et al in 2008 (13).

The scale consists of 52 items six sub-scales. These include spiritual development, interpersonal relationships, nutrition, physical activity, health responsibility and stress management. The sub-scales of the scale are; health responsibility (items 3, 9, 15, 21, 27, 33, 39, 45, 51), physical activity (items $4,10,16,22,28,34,40,46$ ), nutrition (items $2,8,14,20,26,32,38,44,50$ ), spiritual development (items $6,12,18,24,30,36,42,48,52)$, interpersonal relationships (items 1, 7, 13, 19, 25, 31, 37, 43, 49) and stress management (items 5, 11, 17, 23, 29, 35, 41, 47). The 4-point Likert type scale is scored with never " 1 ", sometimes " 2 ", often " 3 " and routinely " 4 ". The lowest and highest scores of the scale are 52 and 208 respectively. It has been stated that the revised scale can be used to determine health promotion behaviors and to evaluate the effectiveness of programs planned for this purpose (13).

The Cronbach's alpha reliability coefficient of the scale was 0.94 for the total scale, and it was ranged from 0.79 to 0.87 for the six sub-scales (4). As a result of the Turkish validity and reliability study of the scale, Cronbach's alpha coefficient has been found to be 0.92 for the whole scale, 0.77 for the health responsibility sub-scale, 0.79 for the physical activity sub-scale, 0.68 for the nutrition sub-scale, 0.79 for the spiritual development sub-scale, 0.80 for the interpersonal relations sub-scale, and 0.64 for the stress management sub-scale (13). 
In this study, Cronbach's alpha coefficient was 0.95 for the whole scale, and it was 0.88 for the health responsibility sub-scale, 0.87 for the physical activity sub-scale, 0.92 for the nutrition sub-scale, 0.93 for the spiritual development sub-scale, 0.85 for the interpersonal relations sub-scale, and 0.91 for the stress management sub-scale.

\section{Ethical issues}

The research followed the tenets of the Declaration of Helsinki. The Ethics Committee of Atatürk University of Medical Sciences approved this study. The institutional ethical committee at Atatürk University of Medical Sciences approved all study protocols (2017-9/2). Accordingly, written informed consent was taken from all participants before any intervention. This study was extracted from master thesis "Evaluation of healthy lifestyle behaviors and affecting factors of HD patients" at this university.

\section{Data analysis}

The data obtained in the study were evaluated using the SPSS 18.0 Statistics program in a computer environment. The $t$ test, Kruskal-Wallis test and Mann-Whitney U test were used for statistical analysis.

\section{Results}

\section{Sample characteristics}

The mean age of the patients was $57.73 \pm 15.28$ years, the mean duration of disease was $8.51 \pm 7.00$ years and the mean duration of $\mathrm{HD}$ was $6.54 \pm 5.55$ years. As a result of the study, it was determined that $52.9 \%$ of the patients were male, $82.1 \%$ were married, $56.4 \%$ had medium income, $64.3 \%$ were literate/primary school graduate and $61.4 \%$ were unemployed. Of the patients included in the study, $66.4 \%$ was found to adhere his/her diet. It was found that $78.6 \%$ of the patients did not smoke, $98.6 \%$ did not use alcohol and $97.9 \%$ did not use non-prescription drugs. Of the patients, $71.4 \%$ had an additional disease to CRF.

\section{Distribution of HPLP II and sub-scale average}

Patients' mean total score in the HPLP-II was found to be $117.80 \pm 37.07$. The lowest and highest scores of the scale are 52 and 208 respectively, and patients' score average was found to be moderate. When we look at the mean scores of the patients in the sub-scales of the HPLP-II, it was found that the highest mean score was $22.44 \pm 7.01$ points in the Health Responsibility sub-scale and the lowest mean score was $14.38 \pm 6.70$ points in the Physical Activity sub-scale (Table 1).

\section{The distribution of the mean average of the patients in the} HLPL according to some information characteristic When the mean HPLP-II total and sub-scale scores of the patients were examined according to age groups, the difference between the groups was found to be not statistically significant (Table 2, $P>0.05$ ). Although the difference between the groups was not statistically
Table 1. Distribution of HPLP II and sub-scale average

\begin{tabular}{lll}
\hline Sub-scale & Min-Max & Mean \pm SD \\
\hline Health responsibility & $9-40$ & $22.44 \pm 7.01$ \\
\hline Physical activity & $8-32$ & $14.38 \pm 6.70$ \\
Nutrition & $9-55$ & $20.24 \pm 6.69$ \\
\hline Spiritual development & $9-36$ & $21.32 \pm 6.93$ \\
Interpersonal relationships & $9-57$ & $21.20 \pm 7.74$ \\
Stress management & $8-32$ & $18.20 \pm 5.78$ \\
Total & $52-208$ & $117.80 \pm 37.07$ \\
\hline
\end{tabular}

significant, the lowest HPLP-II total score was $113.20 \pm 36.54$ in 66 years and older (Table 2).

When the statistical relationship between the mean HPLP-II total and sub-scale scores of the patients was evaluated according to gender, a statistically significant difference was found between gender and health responsibility, physical activity, nutrition, spiritual development, interpersonal relations sub-scales and total scores of HPLP II (Table $2, P<0.05$ ). There was no statistically significant difference between gender and stress sub-scale score (Table $2, P>0.05$ ). The mean scores of the male patients in HPLP-II and its all sub-scales were higher than the female patients' mean scores (Table 2).

When the mean HPLP-II total and sub-scale scores of the patients were examined according to their marital status, despite the fact that the mean scores of married patients were higher than single patients, the difference between the groups was not statistically significant (Table 2, $P>0.05$ ). Considering the mean total and sub-scale scores of the patients in the HPLP-II scale, there was a statistically significant difference between the groups in terms of the economic status (Table 2, $P<0.05$ ). The mean total and sub-scale scores of the patients with good economic status were higher than those with moderate and poor economic status (Table 2).

Considering the mean total and sub-scale scores of the patients in the HPLP-II Scale according to their educational status, a statistically significant difference was found between the groups in terms of mean total and sub-scale scores of the scale (Table 2, $P<0.05$ ). Secondary school/ high school graduate patients had the highest scores in health responsibility, physical activity and nutrition subscales, and higher education graduates had the highest spiritual development, interpersonal relations, stress and HPLP-II total scores (Table 2, $P<0.05$ ).

Considering the mean total and sub-scale scores of the patients in the HPLP-II scale according to their employment status, a statistically significant difference was found between the groups in terms of mean total and sub-scale scores of the HPLP-II scale (Table 2, $P<0.05$ ). The mean scores of the employed patients in HPLP-II scale and its all sub-scales were higher than those that of unemployed and retired (Table 2, $P<0.05$ )

There was no statistically significant difference between 
Table 2. The distribution of the mean average of the patients in the HLPL according to some information characteristic

\begin{tabular}{|c|c|c|c|c|c|c|c|c|}
\hline $\begin{array}{l}\text { Information } \\
\text { Characterstic }\end{array}$ & No. $(\%)$ & $\begin{array}{l}\text { Health Responsibility } \\
\text { Mean } \pm \text { SD }\end{array}$ & $\begin{array}{l}\text { Physical Activity } \\
\text { Mean } \pm \text { SD }\end{array}$ & $\begin{array}{l}\text { Nutrition } \\
\text { Mean } \pm \text { SD }\end{array}$ & $\begin{array}{l}\text { Spiritual Development } \\
\text { Mean } \pm \text { SD }\end{array}$ & $\begin{array}{l}\text { Interpersonal Relationships } \\
\text { Mean } \pm \text { SD }\end{array}$ & $\begin{array}{l}\text { Stress } \\
\text { Mean } \pm S D\end{array}$ & $\begin{array}{l}\text { HPLP II } \\
\text { Total, Mean } \pm \text { SD }\end{array}$ \\
\hline \multicolumn{9}{|l|}{ Years } \\
\hline $20-35$ & $10(6.9)$ & $21.10 \pm 7.60$ & $14.70 \pm 6.49$ & $19.10 \pm 5.36$ & $21.30 \pm 7.71$ & $21.40 \pm 9.00$ & $17.40 \pm 5.81$ & $115.00 \pm 38.96$ \\
\hline $36-50$ & $27(18.3)$ & $22.31 \pm 7.21$ & $15.00 \pm 7.13$ & $20.25 \pm 6.47$ & $21.70 \pm 7.51$ & $21.03 \pm 7.77$ & $18.74 \pm 6.38$ & $119.00 \pm 41.07$ \\
\hline $51-65$ & $50(36.9)$ & $22.04 \pm 6.32$ & $15.02 \pm 6.76$ & $21.58 \pm 7.31$ & $21.88 \pm 6.63$ & $21.94 \pm 6.61$ & $19.06 \pm 5.51$ & $122.52 \pm 35.48$ \\
\hline \multirow[t]{2}{*}{$\geq 66$} & $53(37.9)$ & $22.16 \pm 7.55$ & $13.41 \pm 6.52$ & $19.18 \pm 6.36$ & $20.60 \pm 6.89$ & $20.54 \pm 8.59$ & $17.28 \pm 5.71$ & $113.20 \pm 36.54$ \\
\hline & & KW:0.957, P>0.05 & KW:2.344, $P>0.05$ & KW:3.975, P>0.05 & KW:0.735, P>0.05 & KW:2.025, P>0.05 & $K W: 2.401, P>0.05$ & $\mathrm{KW}: 1.505, P>0.05$ \\
\hline \multicolumn{9}{|l|}{ Gender } \\
\hline Female & $66(47.1)$ & $21.07 \pm 6.95$ & $12.92 \pm 6.60$ & $18.59 \pm 5.89$ & $19.56 \pm 6.73$ & $19.75 \pm 8.40$ & $17.15 \pm 5.63$ & $109.06 \pm 36.83$ \\
\hline \multirow[t]{2}{*}{ Male } & $74(52.9)$ & $23.66 \pm 6.89$ & $15.68 \pm 6.56$ & $21.71 \pm 7.05$ & $22.89 \pm 6.77$ & $22.48 \pm 6.91$ & $19.14 \pm 5.76$ & $125.59 \pm 36.74$ \\
\hline & & MWU: $1358.000, P<0.05$ & MWU:1751.500, $P<0.05$ & MWU:1807.500, $P>0.05$ & MWU:1295.000, $P<0.05$ & MWU:1850.500, $P<0.05$ & MWU:1982.500, $P>0.05$ & MWU:1875.500, $P<0.05$ \\
\hline \multicolumn{9}{|l|}{ Marital status } \\
\hline Married & $115(82.1)$ & $22.56 \pm 7.06$ & $14.40 \pm 6065$ & $20.48 \pm 6.97$ & $21.49 \pm 6.89$ & $21.32 \pm 7.74$ & $18.35 \pm 5.78$ & $118.63 \pm 37.06$ \\
\hline \multirow[t]{2}{*}{ Single } & $25(17.9)$ & $21.88 \pm 6.88$ & $14.28 \pm 7.06$ & $19.12 \pm 5.22$ & $20.52 \pm 7.21$ & $20.64 \pm 7.90$ & $17.52 \pm 5.85$ & $113.96 \pm 37.60$ \\
\hline & & MWU: $1358.000, P>0.05$ & MWU:1385.500, $P>0.05$ & MWU:1253.500, $P>0.05$ & MWU:1295.000, $P>0.05$ & MWU:1357.000, $P>0.05$ & MWU:1292.500, $P>0.05$ & MWU:1315.000, $P>0.05$ \\
\hline \multicolumn{9}{|l|}{ Economic status } \\
\hline Poor & $46(32.9)$ & $19.15 \pm 6.10$ & $11.63 \pm 4.21$ & $17.15 \pm 4.64$ & $17.82 \pm 5.90$ & $17.50 \pm 6.24$ & $15.26 \pm 4.49$ & $98.52 \pm 29.19$ \\
\hline Medium & $79(56.4)$ & $22.24 \pm 6.31$ & $15.08 \pm 6.82$ & $20.97 \pm 5.74$ & $22.31 \pm 6.20$ & $22.31 \pm 7.62$ & $19.02 \pm 5.33$ & $122.96 \pm 33.69$ \\
\hline \multirow[t]{2}{*}{ Good } & $15(10.7)$ & $28.33 \pm 8.39$ & $19.13 \pm 8.80$ & $25.86 \pm 11.13$ & $28.80 \pm 8.55$ & $26.66 \pm 7.90$ & $22.93 \pm 7.23$ & $149.73 \pm 49.01$ \\
\hline & & KW:1.826, $P<0.05$ & KW:1.364 p<0.05 & KW:1.981, $P<0.05$ & $\mathrm{KW}: 2.034, P<0.05$ & KW:1.958, $P<0.05$ & KW:1.979, $P<0.05$ & $\mathrm{KW}: 2.196, P<0.05$ \\
\hline \multicolumn{9}{|l|}{ Education } \\
\hline Illiterate & $9(6.4)$ & $20.00 \pm 5.63$ & $20.00 \pm 5.63$ & $18.22 \pm 5.26$ & $17.77 \pm 5.60$ & $17.33 \pm 5.52$ & $15.22 \pm 4.60$ & $98.00 \pm 24.86$ \\
\hline Literate/Primary & $90(64.3)$ & $20.81 \pm 6.34$ & $20.81 \pm 6.34$ & $19.07 \pm 5.68$ & $19.63 \pm 5.91$ & $19.34 \pm 6.28$ & $16.92 \pm 4.82$ & $108.70 \pm 31.23$ \\
\hline Secondary education & $34(24.3)$ & $26.70 \pm 6.88$ & $26.70 \pm 6.88$ & $23.47 \pm 8.16$ & $25.73 \pm 7.12$ & $25.38 \pm 7.20$ & $21.61 \pm 6.31$ & $141.70 \pm 38.52$ \\
\hline \multirow[t]{2}{*}{ Higher education } & $7(5.0)$ & $25.85 \pm 8.61$ & $25.85 \pm 8.61$ & $22.14 \pm 8.13$ & $26.14 \pm 8.66$ & $29.71 \pm 14.82$ & $22.00 \pm 7.93$ & $144.14 \pm 49.95$ \\
\hline & & KW:1.846, $\quad P<0.05$ & $K W: 1.846, P<0.05$ & KW:9.272, $P<0.05$ & KW:1.968, P<0.05 & $K W: 2.042, P<0.05$ & $\mathrm{KW}: 1.773, P<0.05$ & $\mathrm{KW}: 2.168, P<0.05$ \\
\hline \multicolumn{9}{|l|}{ Employment } \\
\hline Unemployed & $86(61.4)$ & $25.25 \pm 6.66$ & $12.91 \pm 5.96$ & $18.45 \pm 5.55$ & $19.18 \pm 6.50$ & $18.88 \pm 6.91$ & $16.59 \pm 5.39$ & $106.26 \pm 34.32$ \\
\hline Employed & $8(5.7)$ & $29.50 \pm 6.45$ & $18.87 \pm 8.59$ & $25.75 \pm 7.28$ & $29.25 \pm 6.79$ & $28.62 \pm 6.09$ & $24.75 \pm 5.94$ & $156.75 \pm 37.90$ \\
\hline \multirow[t]{2}{*}{ Retired } & $46(32.9)$ & $25.30 \pm 5.95$ & $16.34 \pm 6.91$ & $22.63 \pm 7.69$ & $23.93 \pm 5.88$ & $24.23 \pm 7.72$ & $20.13 \pm 5.13$ & $132.58 \pm 32.37$ \\
\hline & & KW:2.391, $\mathrm{p}<0.05$ & $\mathrm{KW}: 1.180, P<0.05$ & KW:1.791, $P<0.05$ & $K W: 2.432, P<0.05$ & $K W: 2.419, P<0.05$ & $\mathrm{KW}: 2.006, P<0.05$ & $\mathrm{KW}: 2.545, P<0.05$ \\
\hline
\end{tabular}


the HPLP-II total score and sub-scale scores of the groups according to the duration of illness, duration of HD treatment and smoking, alcohol use, non-prescription medication status (Tables 3 and $4, P>0.05$ ).

When the relationship between the HPLP-II total and sub-scale scores of the patients was examined according to the presence of another chronic disease, a significant difference was found in physical activity, spiritual development, interpersonal relations and stress sub-scale scale scores and the total score of the HPLP-II (Table $5, P<0.05)$, and the mean score of patients without any chronic disease other than CRF was higher than the mean score of patients with another chronic disease (Table 5). There was no statistically significant relationship between the health responsibility and nutrition sub-scale scores of the patients in terms presence of another chronic disease (Table 5, $P>0.05$ ).

A statistically significant difference was found between the two groups when the relationship between the adherence to the diet and the HPLP-II total and sub-scale scale scores were examined (Table $5, P<0.05$ ). The mean scores of the patients who adhere to diet in HPLP-II scale total and its all sub-scales were higher than the patients who failed to adhere to the diet (Table 5).

\section{Discussion}

As a result of the study, patients' mean total score in the HPLP-II was found to be $117.80 \pm 37.07$. It was found that the highest mean score was $22.44 \pm 7.01$ points in the health responsibility sub-scale of the HPLP-II and the lowest mean score was $14.38 \pm 6.70$ points in the physical activity sub-scale (Table 1 ). In the study by Özkaraman et al (14), the mean HPLP-II total score of the patients was $137.34 \pm 25.38$ and the highest and lowest sub-scale scores were $25.66 \pm 4.92$ points in the health responsibility subscale and $13.86 \pm 5.26$ points in the physical activity subscale, respectively. In the study by Başarır and Pakyüz (11), however, the HPLP-II total score was $156.72 \pm 15.53$, and the highest and lowest scores in the HPLP-II sub-scales were in the spiritual development $(31.92 \pm 3.68)$ and the physical activity $(13.39 \pm 4.63)$ sub-scales. Although the total HPLP-II scores of the patients in the studies Başarır and Pakyüz (11) and Özkaraman et al (14) were higher than the results of our study, it was observed that the physical activity is the HPLP-II sub-scale where the patients had the lowest scores. Although the positive effects of physical activity on health and well-being are known, there are many studies reporting that most of HD patients have a sedentary life (19-23). Significant reduction in physical function in HD patients is believed to be caused by both disease process and HD treatment.

Although there was no significant difference between the age groups and the HPLP-II total and sub-scale scores in the study, the lowest HPLP-II total score was $113.20 \pm 36.54$ in the 66 years and older age group $(P>0.05$, Table 2$)$. Similar to our results, in the study by Başarır and Pakyüz
(11) and Kiajamali (24), the total HPLP-II score has been found to decrease as age increased. Older age causes decrease in health-promoting behaviors in HD patients as well as decreasing quality of life (24). Considering that aging leads to numerous physical and mental deficiencies, decrease in health-promoting behaviors with increasing age is an expected outcome.

When the statistical relationship between the mean HPLP-II total and sub-scale scores of the patients was evaluated according to gender, a statistically significant difference was found between gender and health responsibility, physical activity, spiritual development, interpersonal relations sub-scales and total scores of HPLP II, and that male patients was found to have higher mean scores than that of female patients (Table 2, $P<0.05$ ). Similar results have also been obtained in other studies conducted to determine health-promoting behaviors in HD patients, and male patients have been found to have higher total HPLP-II score than female patients $(11,15)$. In the thesis study by Akın et al (26) on the quality of life of HD patients in terms of "gender perspective", the quality of life of males have been found to be higher than that of females, and male patients have been found to go home and sleep after an HD session, whereas female patients have been found to go home to provide care for their children and do housework. It is believed that this decrease in the mean score of female patients is due to the traditional structure of the Turkish society, and the study results support this view.

When the mean HPLP-II total and sub-scale scores of the patients were examined according to their marital status, despite the fact that the mean scores of married patients were higher than single patients, the difference between the groups was not statistically significant (Table 2, $P>0.05)$. Similar to our research results, Başarır and Pakyüz (11) have found a significant difference between HPLP-II mean total scores in terms of marital status. They have also found that married patients have higher mean scores than single patients. In the study by Özkaraman et al (14), a significant difference has been found between HPLP-II total scores in terms of marital status, and married patients have been found to have higher mean scores. It is believed that marital status positively affects patients' well-being and health-promoting behaviors by increasing social support. These results are similar to our research findings.

In the study, a statistically significant difference was found between the groups in terms of the economic status considering the relationship between mean total and sub-scale scores of the patients in the HPLP-II Scale. The mean total and sub-scale scores of the patients with good economic status were higher than those with moderate and poor economic status (Table 2, $P<0.05$ ). Similarly, in the study by Özkaraman et al (14) a significant difference has been found between the HPLP-II scores in terms of the economic status. Economic status is an important factor 
Sarıaslan $A$ et al

Table 3. Distribution of Patients' Mean Score from HPLP II according to hemodialysis and disease period

\begin{tabular}{|c|c|c|c|c|c|c|c|c|c|}
\hline $\begin{array}{l}\text { Information } \\
\text { Characteristics }\end{array}$ & $\mathrm{N}$ & $\%$ & $\begin{array}{l}\text { Health Responsibility } \\
\text { Mean } \pm \text { SD }\end{array}$ & $\begin{array}{l}\text { Physical Activity } \\
\text { Mean } \pm \text { SD }\end{array}$ & $\begin{array}{l}\text { Nutrition } \\
\text { Mean } \pm \text { SD }\end{array}$ & $\begin{array}{l}\text { Spiritual Development } \\
\text { Mean } \pm \text { SD }\end{array}$ & $\begin{array}{l}\text { Interpersonal } \\
\text { Relationships } \\
\text { Mean } \pm \text { SD }\end{array}$ & $\begin{array}{l}\text { Stress } \\
\text { Mean } \pm S D\end{array}$ & $\begin{array}{l}\text { HPLP II } \\
\text { Total } \\
\text { Mean } \pm \text { SD }\end{array}$ \\
\hline \multicolumn{10}{|l|}{ Duration of diseases } \\
\hline $1-5$ years & 58 & 41.5 & $23.18 \pm 8.03$ & $16.24 \pm 7.82$ & $21.27 \pm 8.33$ & $22.82 \pm 7.99$ & $22.08 \pm 8.21$ & $19.48 \pm 6.79$ & $125.10 \pm 44.05$ \\
\hline $6-10$ years & 45 & 32.1 & $21.53 \pm 5.84$ & $12.75 \pm 4.12$ & $18.66 \pm 4.34$ & $19.40 \pm 4.68$ & $20.24 \pm 7.48$ & $16.42 \pm 3.70$ & $109.02 \pm 24.63$ \\
\hline $11-15$ years & 22 & 15.7 & $23.18 \pm 7.16$ & $17.72 \pm 7.40$ & $21.36 \pm 6.41$ & $22.68 \pm 7.45$ & $22.63 \pm 7.62$ & $19.50 \pm 5.86$ & $124.09 \pm 39.44$ \\
\hline $16-20$ years & 9 & 6.4 & $20.22 \pm 6.58$ & $13.11 \pm 6.37$ & $18.33 \pm 5.31$ & $18.44 \pm 5.83$ & $17.44 \pm 5.89$ & $16.00 \pm 5.70$ & $103.55 \pm 31.33$ \\
\hline \multirow[t]{2}{*}{21 years and older } & 6 & 4.3 & $22.66 \pm 4.50$ & $9.33 \pm 2.80$ & $20.83 \pm 4.83$ & $20.50 \pm 6.59$ & $20.16 \pm 7.33$ & $17.83 \pm 4.87$ & $111.33 \pm 27.02$ \\
\hline & & & KW:3.096, $P>0.05$ & KW:9.230, P>0.05 & KW:4.415, P>0.05 & $K W: 6.660, P>0.05$ & KW:4.318, P>0.05 & $K W: 8.667, P>0.05$ & $\mathrm{KW}: 4.572, P>0.05$ \\
\hline \multicolumn{10}{|c|}{ Duration of hemodialysis } \\
\hline $1-5$ years & 77 & 55 & $23.36 \pm 7.53$ & $15.76 \pm 7.69$ & $21.42 \pm 7.87$ & $22.62 \pm 7.72$ & $22.14 \pm 7.87$ & $19.41 \pm 6.51$ & $124.74 \pm 41.99$ \\
\hline $6-10$ years & 40 & 28.6 & $21.97 \pm 6.11$ & $13.55 \pm 4.74$ & $18.97 \pm 4.50$ & $20.20 \pm 5.27$ & $20.90 \pm 8.02$ & $16.97 \pm 4.07$ & $112.57 \pm 26.69$ \\
\hline $11-15$ years & 14 & 10 & $20.57 \pm 5.98$ & $11.07 \pm 3.19$ & $19.28 \pm 4.82$ & $19.21 \pm 5.59$ & $18.50 \pm 6.03$ & $16.57 \pm 4.01$ & $105.21 \pm 27.37$ \\
\hline \multirow[t]{2}{*}{16 years and older } & 9 & 6.4 & $19.55 \pm 7.09$ & $11.44 \pm 6.36$ & $17.22 \pm 4.49$ & $18.44 \pm 6.51$ & $18.66 \pm 7.15$ & $15.88 \pm 6.19$ & $101.22 \pm 35.88$ \\
\hline & & & KW:4.005, P>0.05 & $\mathrm{KW}: 7.792, P>0.05$ & $\mathrm{KW}: 4.432, P>0.05$ & KW:5.074, >0.05 & $K W: 3.925, P>0.05$ & $\mathrm{KW}: 6.203, P>0.05$ & KW:5.105, P>0.05 \\
\hline
\end{tabular}


Table 4. The Distribution of patients' average score from the HPLP II according to cigarette, alcohol and non-prescription drug use situations

\begin{tabular}{|c|c|c|c|c|c|c|c|c|c|}
\hline $\begin{array}{l}\text { Information } \\
\text { Characteristics }\end{array}$ & No. & $\%$ & $\begin{array}{l}\text { Health Responsibility } \\
\text { Mean } \pm \text { SD }\end{array}$ & $\begin{array}{l}\text { Physical Activity } \\
\text { Mean } \pm \text { SD }\end{array}$ & $\begin{array}{l}\text { Nutrition } \\
\text { Mean } \pm \text { SD }\end{array}$ & $\begin{array}{l}\text { Spıritual Development } \\
\text { Mean } \pm \text { SD }\end{array}$ & $\begin{array}{l}\text { Interpersonal } \\
\text { Relationships } \\
\text { Mean } \pm \text { SD }\end{array}$ & $\begin{array}{l}\text { Stress } \\
\text { Mean } \pm \text { SD }\end{array}$ & $\begin{array}{l}\text { HPLP II } \\
\text { Total } \\
\text { Mean } \pm \text { SD }\end{array}$ \\
\hline \multicolumn{10}{|l|}{ Smoking status } \\
\hline Yes & 30 & 21.4 & $22.93 \pm 6.13$ & $16.36 \pm 6.72$ & $20.20 \pm 5.44$ & $22.43 \pm 6.73$ & $21.76 \pm 6.97$ & $18.66 \pm 5.57$ & $122.36 \pm 34.06$ \\
\hline \multirow[t]{3}{*}{ No } & 110 & 78.6 & $22.30 \pm 7.25$ & $13.84 \pm 6.62$ & $20.25 \pm 7.02$ & $21.01 \pm 6.98$ & $21.04 \pm 7.96$ & $18.08 \pm 5.86$ & $116.55 \pm 37.90$ \\
\hline & & & MWU:1579.5000 & MWU:1207.500 & MWU:1629.000 & MWU:1691.000 & MWU:1530.500 & MWU:1581.500 & MWU:1481.500 \\
\hline & & & $P>0.05$ & $P>0.05$ & $P>0.05$ & $P>0.05$ & $P>0.05$ & $P>0.05$ & $P>0.05$ \\
\hline \multicolumn{10}{|c|}{ Alcohol use status } \\
\hline Yes & 2 & 1.4 & $24.00 \pm 2.82$ & $13.00 \pm 7.07$ & $17.00 \pm 1.41$ & $19.50 \pm 6.36$ & $19.00 \pm 2.82$ & $17.00 \pm 4.24$ & $109.50 \pm 24.74$ \\
\hline \multirow[t]{3}{*}{ No } & 138 & 98.6 & $22.42 \pm 7.06$ & $14.40 \pm 6.72$ & $20.20 \pm 6.73$ & $21.23 \pm 7.79$ & $21.23 \pm 7.79$ & $18.22 \pm 5.81$ & $117.92 \pm 37.26$ \\
\hline & & & MWU:119.000 & MWU:123.000 & MWU:86.500 & MWU:117.000 & MWU:115.500 & MWU:117.500 & MWU:117.500 \\
\hline & & & $P>0.05$ & $P>0.05$ & $P>0.05$ & $P>0.05$ & $P>0.05$ & $P>0.05$ & $P>0.05$ \\
\hline \multicolumn{10}{|c|}{ Non-prescription drugs } \\
\hline Yes & 3 & 2.1 & $18.00 \pm 7.81$ & $10.33 \pm 4.04$ & $16.00 \pm 7.00$ & $16.33 \pm 8.08$ & $15.66 \pm 6.11$ & $12.66 \pm 4.16$ & $89.00 \pm 35.59$ \\
\hline \multirow[t]{3}{*}{ No } & 137 & 97.9 & $22.54 \pm 6.99$ & $14.47 \pm 6.73$ & $20.33 \pm 6.68$ & $21.43 \pm 6.90$ & $21.32 \pm 7.75$ & $18.32 \pm 5.76$ & $118.43 \pm 36.97$ \\
\hline & & & MWU:135.000 & MWU:115.500 & MWU:130.500 & MWU:124.500 & MWU:115.500 & MWU:80.500 & MWU:109.500 \\
\hline & & & $P>0.05$ & $P>0.05$ & $P>0.05$ & $P>0.05$ & $P>0.05$ & $P>0.05$ & $P>0.05$ \\
\hline
\end{tabular}

Table 5. The distribution of the mean averages of the patients in the SCS II according to the diet compliance and other chronic disease

\begin{tabular}{|c|c|c|c|c|c|c|c|c|c|}
\hline $\begin{array}{l}\text { Information } \\
\text { Characteristics }\end{array}$ & No. & $\%$ & $\begin{array}{l}\text { Health Responsibility } \\
\text { Mean } \pm \text { SD }\end{array}$ & $\begin{array}{l}\text { Physical Activity } \\
\text { Mean } \pm \text { SD }\end{array}$ & $\begin{array}{l}\text { Nutrition } \\
\text { Mean } \pm \text { SD }\end{array}$ & $\begin{array}{l}\text { Spıritual Development } \\
\text { Mean } \pm \text { SD }\end{array}$ & $\begin{array}{l}\text { Interpersonal } \\
\text { Relationships } \\
\text { Mean } \pm \text { SD }\end{array}$ & $\begin{array}{l}\text { Stress } \\
\text { Mean } \pm \mathrm{SD}\end{array}$ & $\begin{array}{l}\text { HPLP II } \\
\text { Total } \\
\text { Mean } \pm \text { SD }\end{array}$ \\
\hline \multicolumn{10}{|c|}{ Additional Disease } \\
\hline Yes & 10 & 71.4 & $21.91 \pm 6.91$ & $13.16 \pm 5.85$ & $19.63 \pm 6.72$ & $20.20 \pm 6.67$ & $20.37 \pm 7.70$ & $17.45 \pm 5.35$ & $112.72 \pm 39.94$ \\
\hline \multirow[t]{3}{*}{ No } & 40 & 28.6 & $23.77 \pm 7.17$ & $17.45 \pm 7.71$ & $21.77 \pm 6.45$ & $24.12 \pm 6.84$ & $23.27 \pm 7.54$ & $20.10 \pm 6.42$ & $130.50 \pm 39.57$ \\
\hline & & & MWU:1740.000 & MWU:1310.500 & MWU:1607.000 & MWU:1385.000 & MWU:1557.500 & MWU:1541.500 & MWU:1513.000 \\
\hline & & & $P>0.05$ & $P<0.05$ & $P>0.05$ & $P<0.05$ & $P<0.05$ & $P<0.05$ & $P<0.05$ \\
\hline \multicolumn{10}{|l|}{ Diet compliance } \\
\hline Yes & 93 & 66.4 & $24.17 \pm 6.67$ & $15.49 \pm 6.84$ & $21.93 \pm 6.79$ & $22.76 \pm 6.79$ & $23.01 \pm 7.76$ & $19.51 \pm 5.61$ & $126.89 \pm 36.36$ \\
\hline \multirow[t]{3}{*}{ No } & 47 & 33.6 & $19.02 \pm 6.44$ & $12.19 \pm 5.87$ & $16.89 \pm 5.08$ & $18.46 \pm 6.35$ & $17.61 \pm 6.39$ & $15.61 \pm 5.21$ & $99.80 \pm 31.77$ \\
\hline & & & MWU:1313.500 & MWU:1207.500 & MWU:1092.500 & MWU:1405.500 & MWU:1290.000 & MWU:1381.000 & MWU:1306.000 \\
\hline & & & $P<0.05$ & $P<0.05$ & $P<0.05$ & $P<0.05$ & $P<0.05$ & $P<0.05$ & $P<0.05$ \\
\hline
\end{tabular}


affecting health-promoting behaviors and it is expected that adequate level of income will contribute positively to health responsibility behaviors.

As a result of the study, when the mean total and subscale scores of the patients in the HPLP-II Scale according to their educational status, a statistically significant difference was found between the groups in terms of mean total and sub-scale scores of the scale (Table 2, $P<0.05$ ). In other studies conducted to determine health-promoting behaviors of HD patients, it has been found that HPLPII total score and sub-scale scores increase significantly as the level of education increases $(11,14,23)$. As the level of education increases, HD patients' health awareness and level of knowledge about the disease increase, the patients fulfill their responsibilities for their own health more, and as a result, their health-promoting behaviors improve.

Considering the mean total and sub-scale scores of the patients in the HPLP-II scale according to their employment status, a statistically significant difference was found between the groups in terms of mean total and sub-scale scores of the HPLP-II scale. The mean scores of the employed patients in HPLP-II and its all sub-scales were higher than those of unemployed and retired patients (Table 2, $P<0.05$ ). The population of employed patients among HD patients is quite limited and the majority of patients are retired $(11,14)$. Loss of social status and social support may occur in unemployed HD patients. This is believed to affect the health-promoting behaviors negatively.

When the duration of HD treatment and duration of disease and HPLP-II total and sub-scale scores of the patients were compared, no statistically significant difference was found between the mean scores of the patients (Table 3, $P>0.05$ ). These results are compatible with the results of Özkaraman et al (14). There are studies in the literature indicating that the duration of disease and duration of dialysis do not affect the quality of life of HD patients $(25,26)$. These studies show that the duration of disease and duration of dialysis do not affect the quality of life and health-promoting behaviors.

As a result of the study, no statistically significant difference was found between the groups when the relationship between smoking, alcohol use, nonprescription medication status of the patients and HPLPII total and sub-scale scale scores were examined (Table 4, $P>0.05)$. In the study by Başarır and Pakyüz (11), there has been no statistically significant difference between smokers and nonsmokers in terms of total HPLP-II score, whereas there has been a significant difference between total scores and physical activity sub-scale scores between the patients who use alcohol and who do not. In our study results, it was surprising that there was no significant difference between HPLP-II total and subscale scores of the HD patients, who smoke, use alcohol and non-prescription drugs. We believe this is due to the low number of patients who smoke, take alcohol and non- prescription drugs.

When the relationship between the HPLP-II total and sub-scale scores of the patients was examined according to the presence of another chronic disease, a significant difference was found in physical activity, spiritual development, interpersonal relations and stress sub-scale scale scores and the total score of the HPLPII (Table 5, $P<0.05$ ). In the literature, it is reported that $90 \%$ of HD patients have an additional chronic disease to ESRD. HD patients often have health problems such as DM, hypertension and coronary artery disease (27). It is expected that having a different chronic disease in addition to $\mathrm{HD}$ treatment will have a negative impact on health-promoting behaviors of patients.

When the relationship between the adherence to diet of the patients who participated in the study and the HPLPII total and sub-scale scale scores were examined, it was found that the mean total and sub-scale scores of the patients who adhered to diet were higher than the patients who did not (Table 5, $P<0.05$ ). One of the most important problems that HD patients have difficulty in adherence to treatment process is compliance with dietary restriction. Adherence to the diet increases the life expectancy and quality of life of the HD patients $(27,28)$. Adherence to diet is an example of health-promoting behavior, and it's expected that patients who adhere to diet have higher HPLP-II Scale total and its all sub-scale scores.

\section{Conclusion}

In this study we found, patients were found to have moderate healthy lifestyle behaviors and very low-physical activity scores. It was concluded that economic status, educational status, working status, presence of another chronic disease and adaptation to diet of the patients affected their healthy lifestyle behaviors.

In light of these results, it can be recommended;

To organize special exercise programs in order to increase the physical activity levels of HD patients with low levels of activity and to provide consultancy through nurses for ensuring participation of $\mathrm{HD}$ patients to these programs, to provide consultancy by nurses to the HD patients in order to improve health-promoting behaviors by taking into account their socio-demographic characteristics such as gender, economic status, education level and employment status, and further support women and those with poor/moderate in economic status, loweducation level and unemployed patients in order to help them acquire health-promoting behaviors.

To provide necessary training by nurses to patients who have another chronic disease in addition to CRF and have problems in adherence to diet, and to repeat training periodically to ensure that the patients achieve the necessary lifestyle changes, and to conduct similar, but multicenter studies with larger sample groups and compare the results. 


\section{Limitations of the study}

The research findings were limited to patients with CRF who were treated in the HD units of the relevant hospitals.

\section{Authors' contribution}

AS and MK were the principal investigators of the study. AS and MK were included in preparing the concept and design. AS and MK revised the manuscript and critically evaluated the intellectual contents. All authors participated in preparing the final draft of the manuscript, revised the manuscript and critically evaluated the intellectual contents. All authors have read and approved the content of the manuscript and confirmed the accuracy or integrity of any part of the work.

\section{Conflicts of interest}

The authors declare that they have no competing interests.

Ethical considerations

Ethical issues (including plagiarism, data fabrication, double publication) have been completely observed by the authors.

\section{Funding/Support}

There is no supporting institution.

\section{References}

1. T. C. Ministry of Health, Turkey Kidney Diseases Prevention and Control Program (2014-2017). http://www.tsn.org.tr. Accessed 8 June 2016

2. Kurbun $\mathrm{H}$, Akten Mİ, Evaluation of self-care power and quality of life in hemodialysis patients. Turk Neph Dial Transpl. 2018; 27:277-87. doi: 10.5262/tndt.2018.3229. [Turkish].

3. Borisov VV, Shilov EM, Chronic renal failure. Urologiia. 2017; 1 Suppl 1:11-8. doi: 10.18565/urol.2017.1-supplement.11-18.

4. U. S. Renal Data System. USRDS Annual Data Report. https:// www.usrds.org. Accessed 13 September 2017.

5. Turkish Society of Nephrology Publications. 2016. T.C. Joint Report of the Ministry of Health and the Turkish Society of Nephrology. http://www.tsn.org.tr. Accessed 10 February 2017.

6. Chan YM, Zalilah MS, Hii SZ. Determinants of compliance behaviours among patients undergoing hemodialysis in malaysia. PLoS One. 2012;7:e41362. doi: 10.1371/journal. pone.0041362.t001.

7. Ma LC, Chang HJ, Liu YM, Hsieh HL, Lo L, Lin MY,et al.Therelationship between health-promoting behaviors and resilience inpatients with chronic kidney disease. Sci World J. 2013;25:124973. doi:10.1155/2013/124973.

8. Shahdadi H, Rahnama M. Experience of nurses in hemodialysis care: a phenomenological study. J Clin Med. 2018;7(2):30. doi: 10.3390/jcm7020030.

9. Pender NJ, Barkauskas VH, Hayman L, Rice VH, Anderson ET. Health promotion and disease prevention: toward excellence in nursing practice and education. Nurs Outlook. 1992;40:106-12.

10. Cürcani M, Tan M, Uremic pruritus and aromatherapy application. J Clin Nurs. 2014; 23: 3356-3365. doi: 10.1111/ jocn.12579.

11. Başarır S, Çınar Pakyüz S. Evaluation of healthy lifestyle behaviors of hemodialysis patients. Nephrol Nurs J. 2015;1:19-
31. [Turkish].

12. Cürcani $M$, Tan $M$, Küçükoğlu S. Healthy lifestyle behaviors and influencing factors of nursing students. J Anatolian Nurs HealTH Sci. 2011;14:;41-49. [Turkish].

13. Bahar Z, Beşer A, Gördes N, et al. The validity and reliability study of the healthy lifestyle behavior scale II. C.U. Cumhuriyet Journal of Nursing. 2008;12(1):1-13. [Turkish].

14. Özkaraman A, Alparslan Balcı G, Gökçe S. Evaluation of healthy lifestyle behaviors of hemodialysis patients. Osman Gazi Med J. 2016;38(2):51-61. doi: 10.20515/otd.54752. [Turkish].

15. Walker SN, Hill-Polerecky DM. Psychometric evaluation of the Health Promoting Lifestyle Profile II. Unpublished manuscript. University of Nebraska Medical Center; 1996.

16. Matheson EM, King DE, Everett CJ. Healthy lifestyle habits and mortality in overweight and obese individuals. J Am Board Fam Med. 2012;25:9-15. doi: 10.1002/14651858.CD009728

17. Sayan A, Erci B. Evaluation of the relationship between health promotion attitudes and behaviors of working women and selfcare power. Journal of Anatolian Nursing and Health Sciences. 2001;4:9-11. [Turkish].

18. Atik D, Coşar AA, Çınar S. Metabolic syndrome and physical activity in hemodialysis patients. J Cont Med. 2014;23:69-75. [Turkish].

19. Hindistan S, Deniz A. Symptom evaluation in patients receiving hemodialysis treatment. Bezmialem Sci. 2018;6: 112-118. doi: 10.14235/bs.2018.1530

20. Leinau L, Murphy TE, Bradley E, et al. Realtions between Conditions Addressed by Hemodialysis Guidelines and NonESRD-Specific Conditions Affecting Quality of Life. Clin J Am Soc Nephrol 2009; 4: 572-578. doi: 10.2215/CJN.03370708

21. Levendoğlu F, Altıntepe L, Uğurlu H. Disability, depression and quality of life in elderly hemodialysis patients. Turk J Geriat. 2004,7:195-198.

22. Mollaoglu M, Kayataş M. Disability is associated with nonadherence to diet and fluid restrictions in end stage renal disease patients undergoing maintenance hemodialysis. Int Urol Nephrol. 2015;47:1863-70. doi: 10.1007/s11255-0151102-1

23. Yurtsever S, Bedük T. Evaluation of fatigue in hemodialysis patients. J Res Dev Nurs. 2003;2:3-10. [Turkish].

24. Kiajamali M, Hosseini M, Estebsari F, Nasiri M, Ashktorab T, Abdi A, et al. Correlation between social support, selfefficacy and health-promoting behavior in hemodialysis patients hospitalized in Karaj in 2015. Electron Physician. 2017:9:4820-7. doi: 10.19082/4820

25. Alemdar H, Çınar PS. To evaluate the effect of self-care power on quality of life in hemodialysis patients. Neprol Nurs J. 2015;2:19-30. [Turkish].

26. Akın A, Demirel S. The concept of gender and its effects on health. J Fac Med. 2003;25:73-82. [Turkish].

27. Elmas A, Saral E, Tugrul A, Şengül E, Bünül F. The relationship between nutritional knowledge and clinical and laboratory findings in hemodialysis patients. Kocaeli Med J. 2012;3:2326. [Turkish].

28. Kurt TY, Erdem E, Kaya C, Karataş A, Arik N. The effect of education on hemodialysis patients on blood pressure and weight gain. Turk J Nephrol. 2012;21:39-44. doi: 10.5262/ tndt.2012.1001.07.[Turkish]. 